The University of Maine

\title{
DigitalCommons@UMaine
}

Earth Science Faculty Scholarship

Earth Sciences

9-17-2003

\section{Seasonal Deuterium Excess in a Tien Shan Ice Core: Influence of Moisture Transport and Recycling in Central Asia}

\author{
Karl J. Kreutz \\ University of Maine - Main, karl.kreutz@maine.edu \\ Cameron P. Wake \\ Vladimir B. Aizen \\ L. DeWayne Cecil \\ Hans-Arno Synal
}

Follow this and additional works at: https://digitalcommons.library.umaine.edu/ers_facpub

Part of the Earth Sciences Commons

\section{Repository Citation}

Kreutz, Karl J.; Wake, Cameron P.; Aizen, Vladimir B.; Cecil, L. DeWayne; and Synal, Hans-Arno, "Seasonal Deuterium Excess in a Tien Shan Ice Core: Influence of Moisture Transport and Recycling in Central Asia" (2003). Earth Science Faculty Scholarship. 79.

https://digitalcommons.library.umaine.edu/ers_facpub/79 


\title{
Seasonal deuterium excess in a Tien Shan ice core: Influence of moisture transport and recycling in Central Asia
}

\author{
Karl J. Kreutz, ${ }^{1}$ Cameron P. Wake, ${ }^{2}$ Vladimir B. Aizen, ${ }^{3}$ L. DeWayne Cecil, ${ }^{4}$ \\ and Hans-Arno Synal ${ }^{5}$
}

Received 4 June 2003; revised 8 August 2003; accepted 14 August 2003; published 17 September 2003.

[1] Stable water isotope $\left(\delta^{18} \mathrm{O}, \delta \mathrm{D}\right)$ data from a high elevation (5100 masl) ice core recovered from the Tien Shan Mountains, Kyrgyzstan, display a seasonal cycle in deuterium excess $\left(d=\delta \mathrm{D}-8^{*} \delta^{18} \mathrm{O}\right)$ related to changes in the regional hydrologic cycle during 1994-2000. While there is a strong correlation $\left(\mathrm{r}^{2}=0.98\right)$ between $\delta^{18} \mathrm{O}$ and $\delta \mathrm{D}$ in the ice core samples, the regression slope (6.9) and mean $d$ value (23.0) are significantly different than the global meteoric water line values. The resulting time-series ice core $d$ profile contains distinct winter maxima and summer minima, with a yearly $d$ amplitude of $\sim 15-20 \%$. Localscale processes that may affect $d$ values preserved in the ice core are not consistent with the observed seasonal variability. Data from Central Asian monitoring sites in the Global Network of Isotopes in Precipitation (GNIP) have similar seasonal $d$ changes. We suggest that regionalscale hydrological conditions, including seasonal changes in moisture source, transport, and recycling in the Caspian/ Aral Sea region, are responsible for the observed spatial and temporal $d$ variability. INDEX TERMS: 1620 Global Change: Climate dynamics (3309); 1655 Global Change: Water cycles (1836); 1040 Geochemistry: Isotopic composition/chemistry; 1827 Hydrology: Glaciology (1863). Citation: Kreutz, K. J., C. P. Wake, V. B. Aizen, L. D. Cecil, and H.-A. Synal, Seasonal deuterium excess in a Tien Shan ice core: Influence of moisture transport and recycling in Central Asia, Geophys. Res. Lett., 30(18), 1922, doi:10.1029/2003GL017896, 2003.

\section{Introduction}

[2] Despite the importance of water resources to a large population in Central Asia, relatively little is known about hydroclimatological variability in the region. The glaciated mountain ranges (Hindu Kush, Pamir, Tien Shan) that form a boundary between the Caspian/Aral Sea drainage basin and the Tibetan Plateau account for a large portion of the available fresh water, mainly in the form of summer melt and subsequent increases in river discharge. While mass and energy balance studies have provided information on the seasonal hydrologic impact of some glaciers in Central Asia [e.g., Aizen et al., 1997], questions remain as to the source

\footnotetext{
${ }^{1}$ Climate Change Institute and Department of Earth Sciences, University of Maine, Orono, Maine, USA.

${ }^{2}$ Climate Change Research Center, Institute for the Study of Earth, Oceans, and Space, University of New Hampshire, Durham, New Hampshire, USA.

${ }^{3}$ Department of Geography, University of Idaho, Moscow, Idaho, USA.

${ }^{4}$ U.S. Geological Survey, Idaho Falls, Idaho, USA.

${ }^{5}$ Institute for Particle Physics, ETH Zürich, Zürich, Switzerland.
}

of moisture that sustains these glacier systems and the interannual to decadal-scale variability in moisture supply. Based on analysis of atmospheric circulation patterns during 1940-1991, at least three different moisture transport regimes (Atlantic, Arctic, Mediterranean) have been identified [Aizen et al., 1995]. The relative importance of each of these sources, as well as the contribution of regional evaporation from the Caspian/Aral Seas and re-evaporation from surrounding desert regions, remains unclear.

[3] The isotopic composition $\left(\delta^{18} \mathrm{O}, \delta \mathrm{D}\right)$ of precipitation represents a powerful tool for investigating the hydrologic cycle on local to global scales, as it reflects the evaporation and condensation history of an air mass. Data collected as part of the Global Network of Isotopes in Precipitation (GNIP) program has served to define baseline information for isotope hydrology studies in several regions, including Southeast Asia [Araguas-Araguas et al., 1998]. GNIP data in the Central Asian region are sparse (Figure 1), however records of precipitation isotopic composition on seasonal to centennial timescales can be developed from selected glaciers in the region. Here we present stable isotope data from a new ice core recovered from the Inilchek Glacier, Central Tien Shan Mountains, Kyrgyzstan (Figure 1), and examine seasonal changes in deuterium excess $[d=\delta \mathrm{D}-$ $8 * \delta^{18} \mathrm{O}$; Dansgaard, 1964]. While the amount of fractionation for each individual isotope system is determined by the degree of distillation that an air mass undergoes during transport, the $d$ value is a second-order parameter that reflects non-equilibrium fractionation during initial evaporation from the ocean, re-evaporation at the land surface, or re-evaporation and/or mixing along the air mass trajectory [Merlivat and Jouzel, 1979]. Our goals in this paper are to 1) compare Inilchek ice core and GNIP isotope data, and identify the mechanisms responsible for observed mean and time series (seasonal) $d$ values in Central Asia, and 2) evaluate recent interannual-scale changes in the Central Asian hydrologic cycle which influenced precipitation regimes in the Tien Shan.

\section{Experimental Methods}

[4] During July/August 2000, two deep ice cores (Core 1, 167.05 m, 5100 masl; and Core 2, 160.48 m, 5120 masl) were drilled on the Inilchek Glacier using a solar powered electromechanical auger. The upper $100 \mathrm{~m}$ of Core 1 was processed into $4 \mathrm{~cm}$ samples using a polycarbonate lathe and saw system and returned frozen to the U.S. for analysis. Stable isotope analyses have been completed on the processed Core 1 samples to a depth of $18.17 \mathrm{~m}$. Oxygen isotope ratios were measured using standard $\mathrm{CO}_{2}$ equilibration techniques $( \pm 0.05 \%$ ), and hydrogen isotope ratios were 


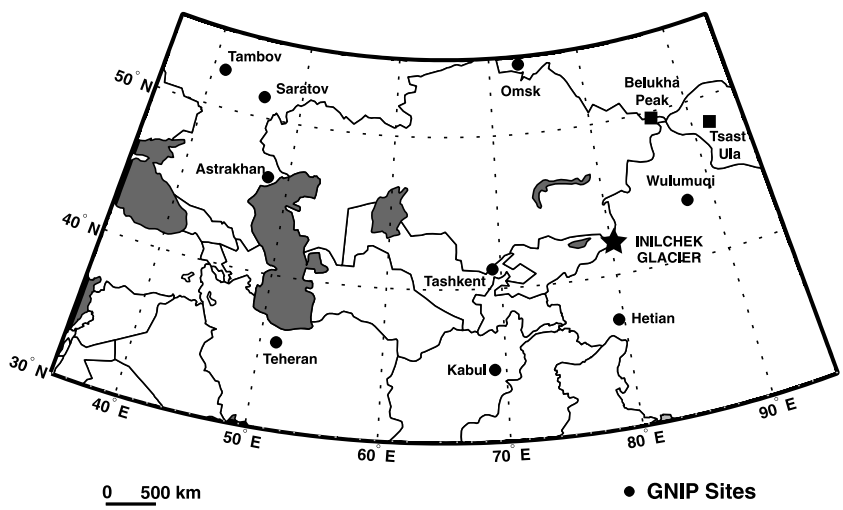

Figure 1. Location map for Central Asia sampling sites.

measured using $\mathrm{Cr}$ reduction in a continuous flow system $( \pm 0.5 \%)$. All data are reported in delta $(\delta)$ notation vs. standard mean ocean water (SMOW).

[5] Isotope profiles from Core 1 display a distinct zone of uniform values $\left(\delta^{18} \mathrm{O}\right.$ mean $=-16.8 \%, 1 \sigma=1.9 \%$ ) from $9.87-15.11 \mathrm{~m}$ depth. Based on visual stratigraphic observations, this zone contains firn with a mottled appearance, as well as several small $(0.5-1.5 \mathrm{~cm})$ stones. This type of stratigraphy is not observed elsewhere in Core 1 , Core 2 ( $\sim 500 \mathrm{~m}$ north), or in a 1998 firn core [ 1500 m north; Kreutz et al., 2001]. We assume that this zone represents a single instantaneous event that deposited $5.24 \mathrm{~m}$ of material,

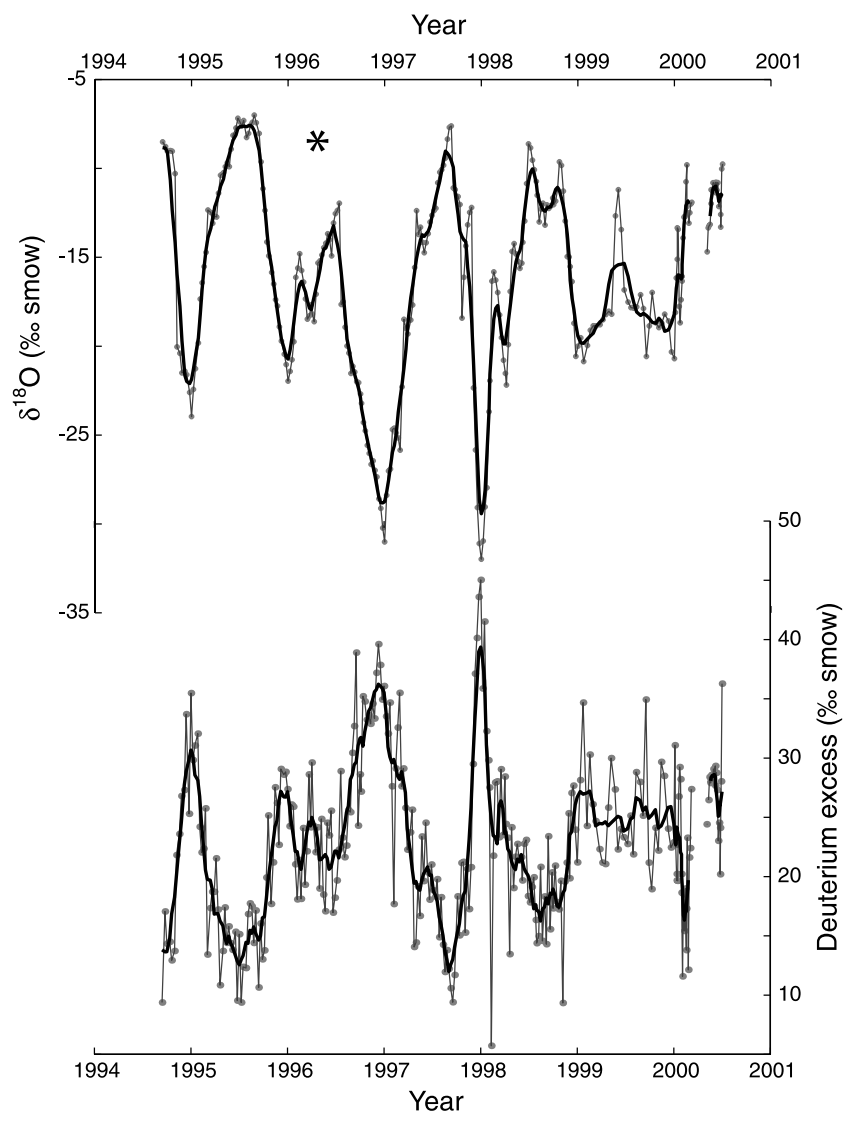

Figure 2. Isotope profiles $\left(\delta^{18} \mathrm{O}\right.$ and $\left.d\right)$ from the Inilchek Glacier 2000 Core 1. Thin grey lines and grey dots represent raw data, and the thick black line is a 5-point running mean in both panels.

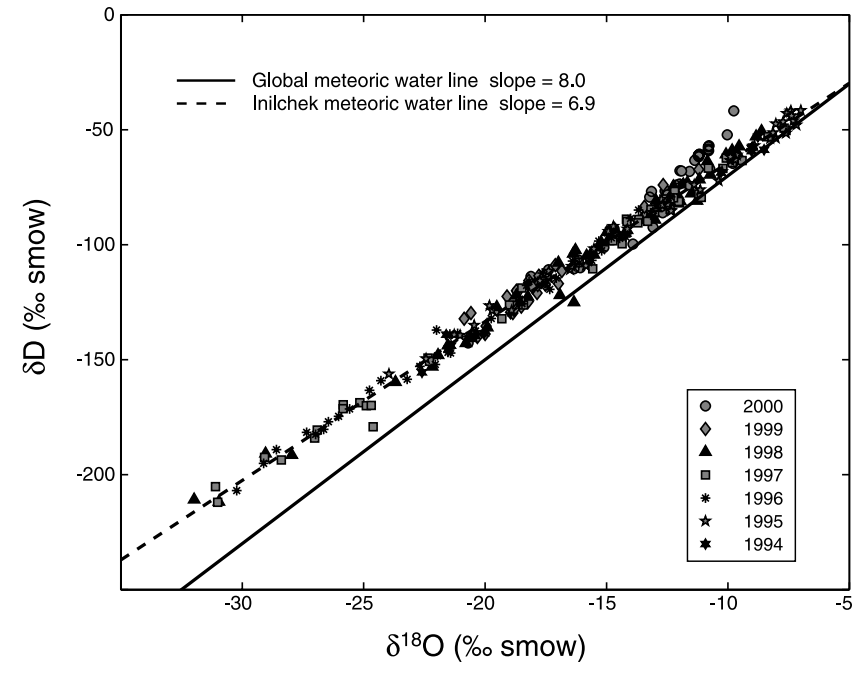

Figure 3. $\delta^{18} \mathrm{O}$ vs. $\delta \mathrm{D}$ in samples from Inilcheck Glacier 2000 Core 1. Separation of data into individual years is based on the depth/age scale presented in Figure 2.

likely a large ice fall from surrounding basin walls. We have therefore removed this portion of the isotope record (marked by an $*$ in Figure 2 ), and dated the core using the seasonal change in $\delta^{18} \mathrm{O}$ (and $\left.\delta \mathrm{D}\right)$ ratios. The rationale for interpreting the first-order $\delta^{18} \mathrm{O}$ variability in terms of seasonal temperature change is based on results of Yao et al. [1999], who found a high correlation $\left(\mathrm{r}^{2}=0.82\right)$ between temperature and precipitation $\delta^{18} \mathrm{O}$ in the eastern Tien Shan. The resulting accumulation rate estimate from the upper $18.17 \mathrm{~m}$ of Core 1 is $1.50 \mathrm{~m}$ water equivalent (WE)/year after correcting for density variation. This estimate agrees with mean accumulation rates calculated from the 1998 firn core $\delta^{18} \mathrm{O}$ profile [1.46 m WE/yr; Kreutz et al., 2001], and from a ${ }^{36} \mathrm{Cl}$ profile from Core 1 that clearly identifies the 1958 atmospheric nuclear weapon test horizon [1.63 m WE/yr; Cecil et al., unpublished data]. Additional support for the Core 1 depth/age relationship is the similarity of $\delta^{18} \mathrm{O}$ profiles from 2000 Core 1 and the 1998 firn core. Both profiles display highly negative $\delta^{18} \mathrm{O}$ values during winter 1996/97 and 1997/98, suggesting that the depth/age scales based on seasonal $\delta^{18} \mathrm{O}$ variations are accurate over the represented time period.

\section{Results and Discussion}

\subsection{Tien Shan Meteoric Water Line and Deuterium} Excess Values

[6] While there is a good correlation $\left(\mathrm{r}^{2}=0.98\right)$ between the two isotope parameters that is independent of sample age (Figure 3 ) or season, the slope of the linear regression (6.9) is significantly different from the global meteoric water line value of 8 [Dansgaard, 1964]. The resulting $d$ profile has distinct seasonality, with low $d$ values during summer and high $d$ values during winter. Based on the $\delta^{18} \mathrm{O}$ profile, the winter seasons of 1997 and 1998 had anomalously low $\delta^{18} \mathrm{O}$ values and the highest seasonal $d$ values. Few seasonal $d$ records from high elevation firn cores in Asia are available for comparison, and those that do exist show various seasonal $\delta^{18} \mathrm{O} / d$ relationships. Firn cores drilled on Belukha Peak (Altai Range, Southern Siberia; Figure 1) have seasonal $\delta^{18} \mathrm{O} / d$ variability similar to the 
Tien Shan [Oliver et al., 2002], while a firn core record from Tsast Ula ice cap (Mongolia; Figure 1) displays an opposite seasonal $\delta^{18} \mathrm{O} / d$ relationship [i.e., higher $d$ in summer; Schotterer et al., 1997].

\subsection{Local Influences on Deuterium Excess Values}

[7] Several possible explanations that involve local-scale processes may account for the large seasonal $d$ variability observed in the Inilchek core profile. Using dynamically simple one-dimensional isotopic models and Antarctic data, Ciais and Jouzel [1994] demonstrated large $d$ sensitivity to the saturation conditions prevailing during snow formation. Higher modeled $d$ values occur at lower snow formation temperatures, and $d$ values changed $\sim 10 \%$ under different condensed phase compositions (e.g., $0 \%, 50 \%$, and 100\% liquid). However, it is not clear if the same applies in high elevation areas in general, and Asia in particular. Regardless, the potential magnitude of this effect does not explain the large (up to $\sim 30 \%$ ) seasonal difference in Inilchek $d$ values. Post-depositional modification of the isotope signal (via melting, evaporation, sublimation, wind erosion, and/or diffusive mixing of water vapor) provides another possible local-scale explanation for the observed Inilchek $d$ profile seasonality. While melting does not significantly affect snowpack $d$ values, subsequent evaporation may over diurnal and longer timescales. Summer temperatures are at $0^{\circ} \mathrm{C}$ in the upper $1 \mathrm{~m}$ snowpack at $5100 \mathrm{~m}$ on the Inilchek Glacier [Aizen et al., 1997], however meltwater formation has not been observed on the surface and percolation is negligible. Evaporative loss of water at the coresite elevation is therefore an unlikely cause of $d$ variation on seasonal timescales. In the Tien Shan, $80 \%$ of the seasonal precipitation occurs in the summer season (June-August), with dry, cold conditions prevailing during winter [Aizen et al., 1997]. Thus, enhanced sublimation is unlikely during the Tien Shan dry season due to extremely low $\left(-40^{\circ} \mathrm{C}\right)$ average winter temperatures, and is unlikely during the summer due to high accumulation rates. There is no seasonal change in the meteoric water line slope for summer and winter samples in the Inilchek core, nor do the slopes approach typical sublimation (evaporation) line slopes $(\sim 5)$. Another possibility is partial evaporation of snow as it falls through an unsaturated air column, analogous to conditions prevalent in warm arid regions [e.g., Gat and Carmi, 1970]. Given the high relative humidity conditions prevalent during the main summer accumulation season [70-95\%; Aizen et al., 1997], it is unlikely that evaporative changes in snowfall $d$ occur at the site that would significantly affect the preserved ice core record. Lastly, diffusive and convective mixing of water vapor during densification acts to smooth the seasonal isotope record and affects $\delta^{18} \mathrm{O}$ and $\delta \mathrm{D}$ differently [Johnsen et al., 2000], leading to alteration of the preserved $d$ signal. Because the record we are examining here is from the upper $18 \mathrm{~m}$ of the Inilchek firn zone, and there is no attenuation of the $\delta^{18} \mathrm{O}, \delta \mathrm{D}$, or $d$ annual signals (Figure 3), we assume that post-depositional smoothing and/or alteration of the isotope signals is not a factor.

\subsection{Regional Isotope Hydrology and Moisture Transport}

[8] Although GNIP data in the region are limited and multi-year precipitation isotope time series are generally not available, the limited datasets can be used to provide information on seasonal isotope variability and compare with surrounding regions. Based on summer-winter differences in precipitation $\delta^{18} \mathrm{O}\left(\Delta \delta^{18} \mathrm{O}\right)$, Araguas-Araguas et al. [1998] demonstrated a clear boundary between stations affected by monsoon precipitation (negative $\Delta \delta^{18} \mathrm{O}$ ) in Asia. The boundary reflects the northward extension of the Indian and Pacific monsoons, and is coincident with the maximum extent of the Intertropical Convergence Zone (ITCZ) in summer. All Central Asian GNIP stations (including Kabul) and the Inilchek ice core display positive $\Delta \delta^{18} \mathrm{O}$ values, indicating little or no influence from monsoon precipitation. This result is consistent with observed mean atmospheric circulation fields over Central Asia, where seasonal changes in the vertically integrated water vapor flux are controlled primarily by the interaction of the Siberian High (SH) and the 500 mbar geopotential height field [Small et al., 1999]. Based on the combination of synoptic and isotope data, we assume that the majority of precipitation reaching the Tien Shan is due to westerlytraveling cyclonic systems and not related to the Indian monsoon.

[9] The high mean $d$ value $(23.0 \%)$ in the Inilchek ice core suggests that moisture reaching the site is either produced under unique conditions, and/or is influenced by additional inputs during advection. Global contour plots of GNIP isotope data show that $d$ values in Central Asia are among the highest observed, both on a mean annual and seasonal basis (see http://isohis.iaea.org/GNIP.asp), and are consistent with the mean Inilchek $d$ value. The ECHAM GCM simulates mean annual $d$ values in Central Asia similar to observed values, due to a high $(>50 \%)$ percentage of precipitation originating from continental recycling [Hoffman et al., 1998]. In particular, the Caspian/Aral Sea region and surrounding deserts represent areas that would provide conditions favorable for moisture revaporation [Hoffman et al., 1998]. Eastward advection of any revaporated moisture from this region would likely impact the Tien Shan, but may be limited on a regional scale. The few existing $d$ data from high elevation precipitation in other mountain regions of Central Asia to the south (Hindu Kush [Niewodniczanski et al., 1981]) and north (Altai [Oliver et al., 2002]) are lower than those observed in the Tien Shan. Moreover, GNIP stations to the north of the Caspian/Aral region display low mean $d$ values. This spatial $d$ pattern likely reflects the limited influence of moisture from the Caspian/Aral Sea to areas directly downwind (east).

[10] While the mean $d$ value in the Inilchek ice core indicates an overall contribution from recycled moisture, the large seasonal change in $d$ is too large to explain with a single moisture source and trajectory. Comparison of Inilchek and GNIP data indicates similar seasonal $d$ changes at Kabul, Tashkent, and inner China stations [AraguasAraguas et al., 1998]. In other arid regions (i.e., eastern Mediterranean), high winter $d$ values are caused by the modification of continental air masses during passage over relatively warm water [Gat and Carmi, 1970]. Low humidity conditions in the winter continental air masses causes rapid evaporation, and hence high $d$ values in subsequent precipitation. In Central Asia, long-range transport of North Atlantic air masses across Eurasia during winter causes 
interaction with the Black, Caspian, and Aral Seas [Small et al., 1999], and air/sea conditions are likely favorable for rapid evaporation and formation of high $d$ vapor. Although precipitation amounts in the Tien Shan during winter are small, a few events with high $d$ values may be responsible for the seasonal ice core profile. During summer, when the majority of precipitation occurs in the Tien Shan, moisture trajectories from the south are more common and humidity conditions in the region favor lower $d$ values. We suggest that the seasonal change in moisture trajectory and air/sea conditions in Central Asia explains the seasonal $d$ change observed in the Inilchek and GNIP datasets.

[11] Based on the Inilchek data (Figure 3), there were substantial changes in regional hydrological conditions during 1994-2000. Winter $\delta^{18} \mathrm{O}(d)$ values during 1997 and 1998 are lower (higher) than in other years by $\sim 10 \%$, perhaps indicating enhanced aridity. Regional-scale atmospheric modeling indicates that high and low North Atlantic Oscillation (NAO) index years are linked to changes in Aral Sea region aridity [Small et al., 1999]. Winter (Dec.-Mar.) NAO values during 1995-1998 are the lowest of the 1990s, and may correspond to higher evaporation minus precipitation (E-P) values in Central Asia [Hurrell et al., 2003]. While the ice core record presented here is too short to evaluate this hypothesis, our results nonetheless point to the value of longer ice core isotope time-series from the Tien Shan and other high-elevation Central Asian sites for studying regional hydroclimatology on interannual to decadal timescales.

\section{Conclusions}

[12] The data and interpretations presented here highlight the complexity inherent in stable isotope records recovered from high-elevation regions of Central Asia. While temperature is likely a first-order control on individual isotope $\left(\delta^{18} \mathrm{O}\right.$ or $\left.\delta \mathrm{D}\right)$ records, the influence of seasonal changes in moisture source and revaporation of moisture from arid regions should be considered. In the the Tien Shan, $d$ values from the Inilchek ice core and surrounding GNIP sites indicate that the contribution of revaporated moisture is potentially significant. Based on the spatial pattern of mean annual $d$ values, we suggest that the influence of the Caspian/Aral Sea on regional hydrology is limited to an area to the east, bordered primarily by the Tien Shan. Further, changes in regional moisture source and trajectory on a seasonal basis are likely necessary to explain the seasonal profile of $d$ values in the Inilchek ice core. The interannual variability observed in the Inilchek $d$ record suggests that there may be links to larger-scale ocean/ atmosphere processes, and thus longer ice core isotope records are needed to interpret late Holocene climate and hydrological variability. Given recent and projected hydrologic change in the region, including glacial and river-dependent systems, an improved understanding of hydroclimatological processes in Central Asia is crucial.
[13] Acknowledgments. We thank our colleagues for their assistance in the field during the 2000 Inilchek Expedition, D. Introne and J. Morrison for stable isotope measurements, and support from the National Science Foundation, the Department of Energy, and the U.S. Geological Survey.

\section{References}

Aizen, V. B., E. M. Aizen, and J. M. Melack, Climate, snow cover and runoff in the Tien Shan, Water Resources Bulletin, 31(6), 1-17, 1995.

Aizen, V. B., E. M. Aizen, J. Dozier, J. M. Melack, D. D. Sexton, and N. Nesterov, Glacial regime of the highest Tien Shan mountain, PobedaKhan Tengry massif, J. Glaciology, 43(145), 503-512, 1997.

Araguas-Araguas, L., K. Froehlich, and K. Rozanski, Stable isotopic composition of precipitaton over southeast Asia, J. Geophys. Res., 103(D22), 28,721-28,742, 1998.

Ciais, P., and J. Jouzel, Deuterium and Oxygen 18 in precipitation: Isotopic model, including mixed cloud processes, J. Geophys. Res., 99(D8), $16,793-16,803,1994$.

Dansgaard, W., Stable isotopes in precipitation, Tellus, 16, 436-468, 1964. Gat, J. R., and I. Carmi, Evolution of the isotopic composition of atmospheric waters in the Mediterranean Sea Area, J. Geophys. Res., 75(15), 3039-3048, 1970.

Hoffman, G., M. Werner, and M. Heimann, Water isotope module of the ECHAM atmospheric general circulation model: A study on timescales from days to several years, J. Geophys. Res., 103(D14), 16,871-16,896, 1998.

Hurrell, J. W., Y. Kushnir, G. Ottersen, and M. Visbeck, An overview of the North Atlantic Oscillation, in The North Atlantic Oscillation: Climatic Significance and Environmental Impact, edited by J. W. Hurrell, Y. Kushnir, G. Ottersen, and M. Visbeck, 1-35, AGU, Washington, D. C., 2003.

Johnsen, S. J., H. B. Clausen, K. M. Cuffey, G. Hoffman, J. Schwander, and T. Creyts, Diffusion of stable isotopes in polar firn and ice: The isotope effect in firn diffusion, in Physics of Ice Core Records, edited by T. Hondoh, 121-140, Hokkaido Univ. Press, Sapporo, 2000.

Kreutz, K. J., V. B. Aizen, L. D. Cecil, and C. P. Wake, Oxygen isotopic and soluble ionic composition of precipitation recorded in a shallow firn core, Inilchek Glacier (Central Tien Shan), J. Glaciology, 47(159), 548554, 2001.

Merlivat, L., and J. Jouzel, Global climatic interpretation of the DeuteriumOxygen 18 relationship for precipitation, J. Geophys. Res., 84(C8), 5029-5033, 1979.

Niewodniczanski, J., J. Grabczak, L. Baranski, and J. Rzepka, The altitude effect on the isotopic composition of snow in high moutains, J. Glaciology, 27(95), 99-111, 1981.

Oliver, S., M. Schwikowski, B. Rufibach, H. Gaggeler, P. Ginot, M. Luthi, T. Papina, S. Eyrik, M. Saurer, S. Bajo, and J. Eikenberg, Preliminary results from glacio-chemical investigation of an ice core from Belukha Glacier, Siberian Altai, pp. 18, Univ. of Bern and Paul Scherrer Insitute, 2002.

Schotterer, U., K. Fröhlich, H. W. Gäggeler, S. Sandjordj, and W. Stichler, Isotope records from Mongolian and alpine ice cores as climate indicators, Climatic Change, 36, 519-530, 1997.

Small, E. E., F. Giorgi, and L. C. Sloan, Regional climate model simulation of precipitation in central Asia: Mean and interannual variability, J. Geophys. Res., 104(D6), 6563-6582, 1999.

Yao, T., V. Masson, J. Jouzel, M. Stievenard, S. Weizen, and J. Keqin, Relationships between $\delta^{18} \mathrm{O}$ in precipitation and surface air temperature in the Urumqi River Basin, east Tienshan Mountains, China, Geophys. Res. Lett., 26(23), 3473-3476, 1999.

K. J. Kreutz, Climate Change Institute and Department of Earth Sciences, University of Maine, Orono, ME 04469, USA. (karl.kreutz@maine.edu)

C. P. Wake, Climate Change Research Center, Institute for the Study of Earth, Oceans, and Space, University of New Hampshire, Durham, NH 03824, USA.

V. B. Aizen, Department of Geography, University of Idaho, Moscow, ID 84844, USA.

L. D. Cecil, U.S. Geological Survey, 900 Skyline Drive Suite C, Idaho Falls, ID 83402, USA.

H.-A. Synal, Institute for Particle Physics, ETH Zürich, CH-8093 Zürich, Switzerland. 